\title{
New copolymerizable photoinitiators for radiation curing of acrylic PSA
}

\author{
Zbigniew Czech*, Dominika Sowa, Paulina Ragańska \\ Institute of Chemical Organic Technology, West Pomeranian University of Technology, Szczecin, \\ K. Pulaskiego 10, 70-322 Szczecin, Poland
}

*E-mail address: psa_czech@wp.pl

\section{ABSTRACT}

This article presents a new class of copolymerizable vinyloxycarbonyl groups, known such as organic carbonate or carba te. el copo nerizable photoinitiators have been prepared through the reaction between y yl chloron te ald hydroxyl groups containing photoreactive derivatives such as benzophen o cetopheno, benzoine-and anthrachinone-derivatives. The main emphasis is given to inf ce of this new class of unsaturated photoinitiators on UV-crosslinking process of as pressure sitive adhesives (PSA). Moreover, the paper describes the influence of various $\mathrm{p}$ rameters such as $/$-initiated crosslinking time and concentration of unsaturated photoinitiators n relevant PSA properties like tack, peel adhesion and shear strength (cohesion).

Keywords: copolymerizable photoinitiators; acrylics; tack; peel adhesion; shear strength

\section{INTRODUCTION}
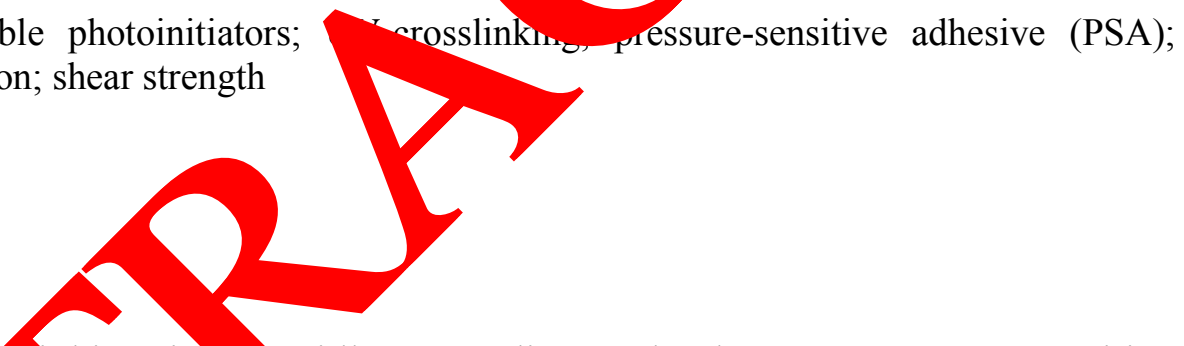

UV-inducted cros

'king is orsidly expanding technology on pressure-sensitive adhesives area resul $\mathrm{g}$ fl its main advantages such as solvent-free process, efficient and economical energ sed and properties and quality of chemical crosslinking bonding [1]. This photocro sinki o process and interesting application for producing photoreactive PSA systems use. the owin industry for paints, printing, inks, dental materials, adhesives and self-adhesive ta

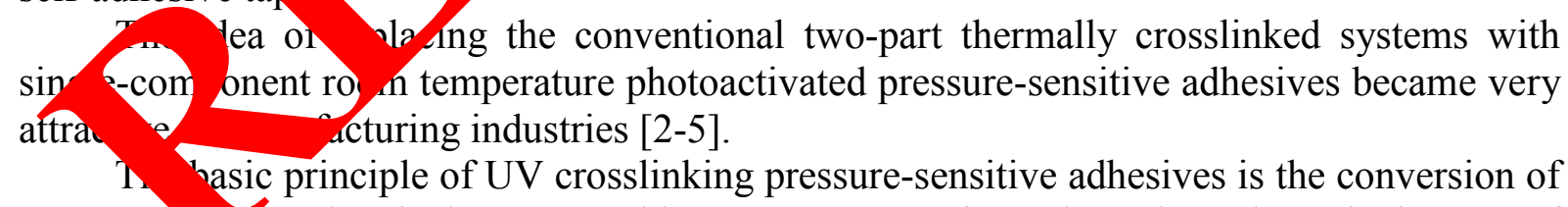
UV energ. Ato chemical energy. This energy conversion takes place through the use of chemical species (photoinitiators) which, upon absorption of a particular wavelength of light, produce photochemically reactive radicals capable of initiating a rapid chain reaction. With the use of commonly available light sources it can be calculated that as many as $10^{19}$ initiating photoinitiators per second can be generated. It is therefore not surprising that the radiation crosslinking systems on the market today can be crosslinked so rapidly that it is sometimes in less than one second [6]. 
The most important features of the crosslinked acrylic pressure-sensitive adhesives, such as tack, peel adhesion and shear strength can be controlled by the UV dosage. The crosslinking of PSA with ultraviolet radiation can be done directly after the application.

The crosslinking mechanism of UV photoreactive acrylics PSA containing copolymerizable photoinitiators has been thoroughly investigated and it is presented schematically (Fig. 1) [7-10].

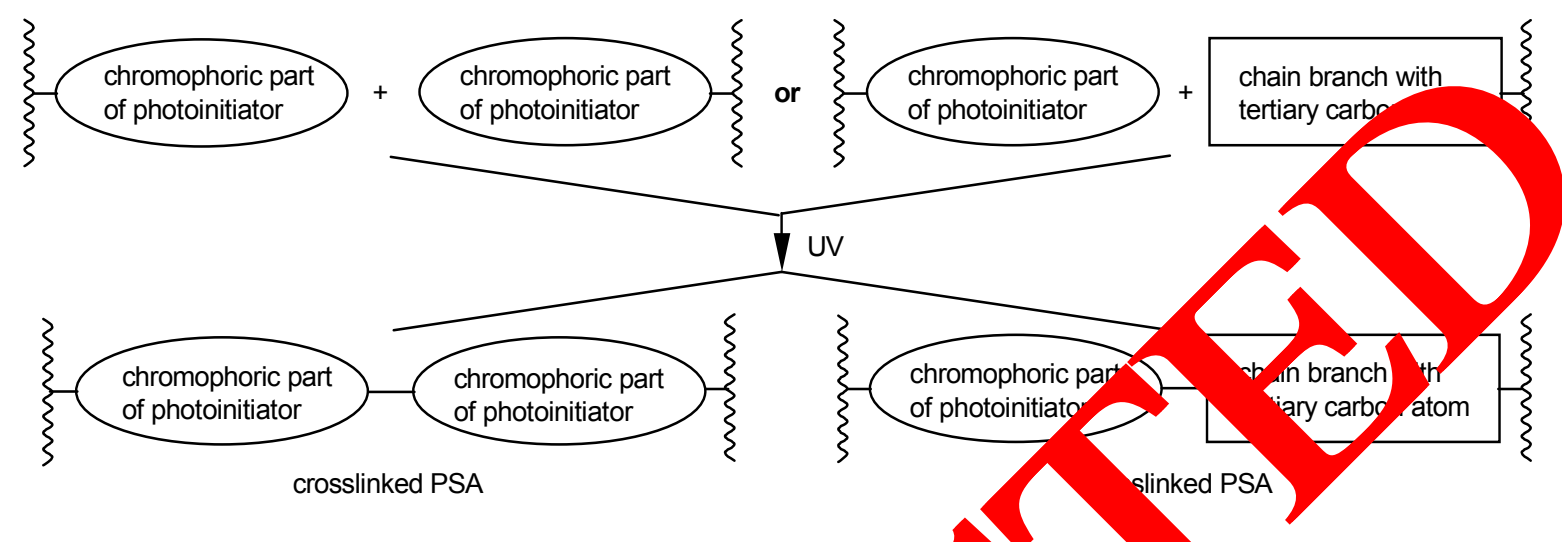

Figure 1. Photocrosslinking by using of unsaturated phot initiators incorpor d into polymer chain.

During UV exposition the intermolecular phitiato $\mathrm{H}$-abstractors structures are excited and react with the neighbouring $\mathrm{C}-\mathrm{K}$ sitions or smer side-chains.

UV-crosslinkable acrylic pressure-sensitive ann oxsess excellent oxidation resistance which allows working without inert gas atmos he e $\left[\mathrm{T}_{\mathrm{y}}\right.$

\section{EXPERIMENTAL}

\section{1. Materials}

The following xpe ents wery conducted to study the influence of a new class of copolymerizable givinitia on diverse main acrylic PSA properties, such as: viscosity, molar mass, to ck, pel adhesio, and shear strength. The acrylic PSAs were synthesized using betwe 2 ap 4, 5 wt. \% (step 0.5 wt. \%) 2-ethylhexyl acrylate (2-EHA), 30 wt. \% methyl acrylato A), 5 y $\%$ acrylic acid (AA) and between 0.5 and 3 wt. \% (step 0.5 wt. $\%$ ) in ted a yp erizable photoinitiators during polymerization in a typical organic soly nt lik ethyl ace we with polymer content of $50 \%$ by weight $[12,13]$.

acrylate (2-EHA), methyl acrylate (MA), acrylic acid (AA) and ethyl acetate re avallable from Poly-Chem (Germany).

The olymerizable photoinitiators ( $\alpha$-cleavage type I and hydrogen abstraction type II) were synthesized at Szczecin University of Technology (Poland) through the reaction between vinyl chloroformate and hydroxyl groups containing photoreactive derivatives. The following copolymerizable photoinitiators (Fig. 2) have been prepared according [11]. 
<smiles>C=COC(=O)Oc1ccc(C(=O)c2ccccc2)cc1</smiles>

4-Benzophenylvinyl carbonate (hydrogen abstraction type II)

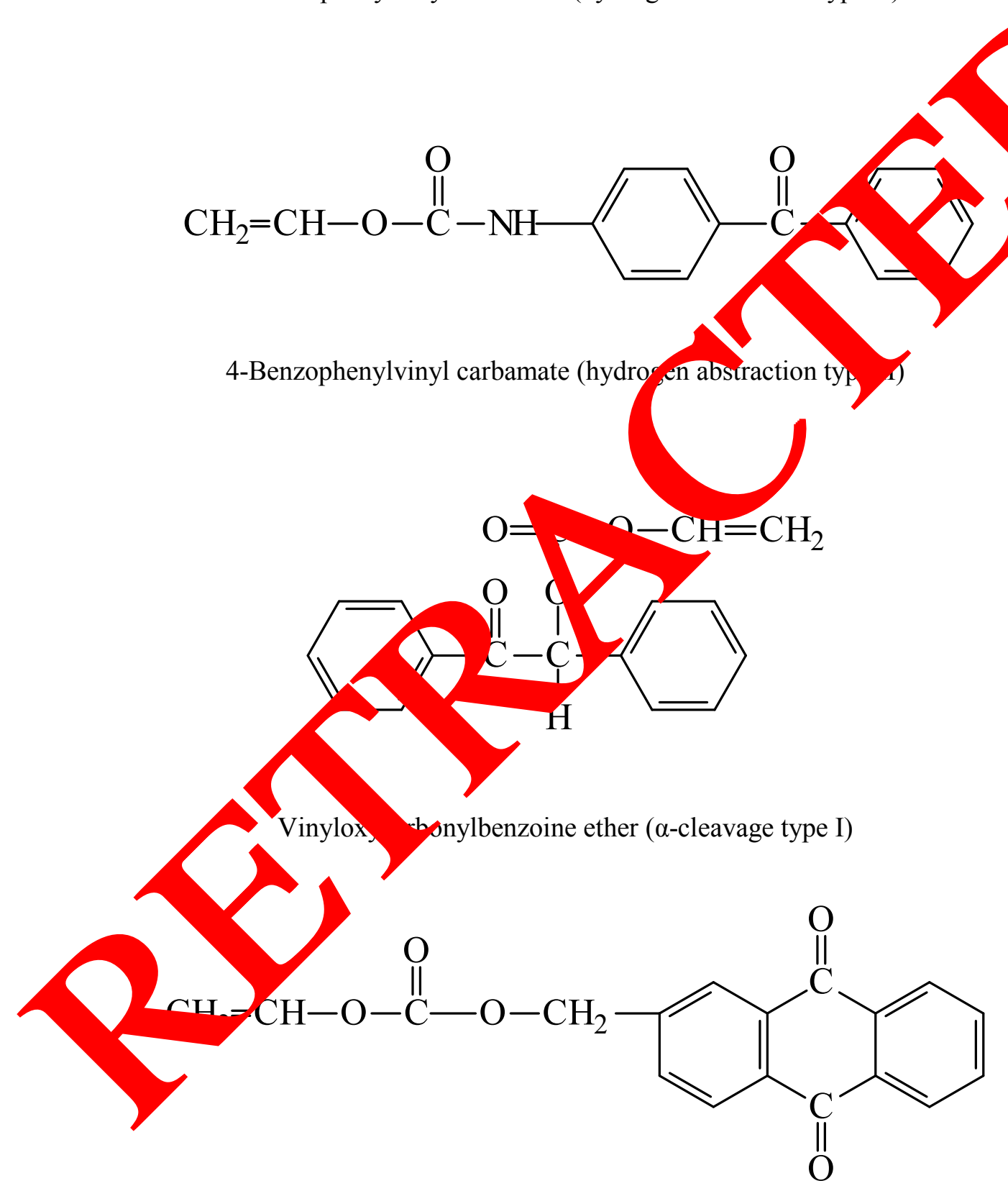

2-Vinyloxycarbonyloxymethyl anthrachinone (hydrogen abstraction type II)

Figure 2. New class of investigated copolymerizable photoinitiators. 


\section{2. Evaluation of PSA properties}

Tack, peel adhesion and shear strength of investigated photoreactive acrylic pressuresensitive adhesives were measured according to AFERA 4015 (tack), 4001 (peel adhesion) and 4012 (shear strength).

The UV-crosslinkable acrylic PSA were coated with $60 \mathrm{~g} / \mathrm{m}^{2}$ coating weight directly on a polyester foil and later after drying crosslinked under UV lamp of type U 350-M-I-DL from IST Company (Germany). The resulted samples were cut into one-inch strips and applied to stainless steel. The tack, peel adhesion and shear strength were measured on Zwick testing machine after a specified 1 week dwell period.

\section{3. UV-absorption of investigated photoinitiators}

The UV-absorption curves of investigated copolymerizable conducted using Hewlett Packard Diode Array UV/VIS Spectrophot mete and Figure 3.
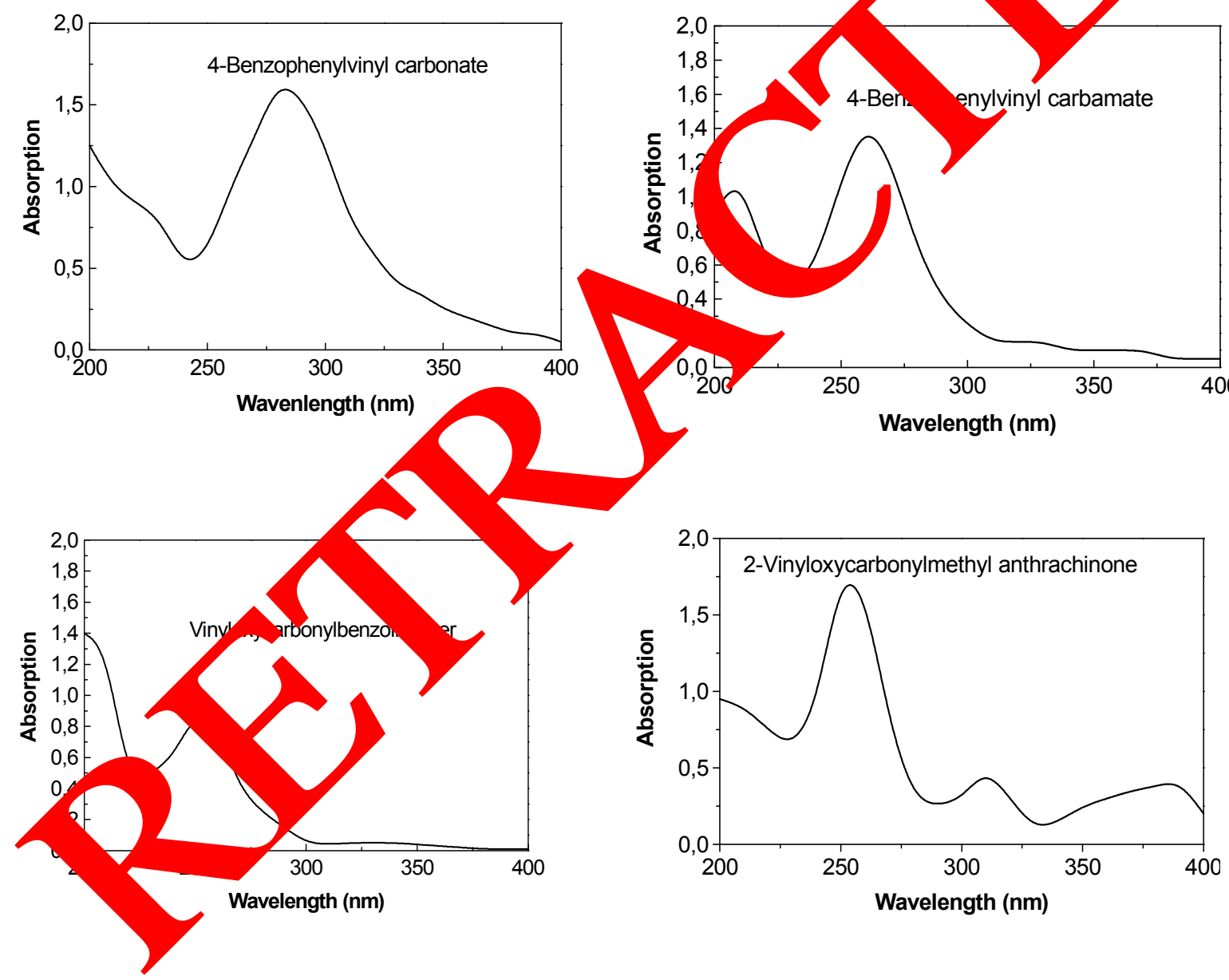

Figure 3. UV-absorption curves of investigated copolymerizable photoinitiators. 
The UV-absorption curve of 4-benzophenylvinyl carbonate shows strong absorption at $280 \mathrm{~nm}$, of 4-benzophenylvinyl carbamate at $263 \mathrm{~nm}$, of vinyloxycarbonylbenzoine ether at $255 \mathrm{~nm}$ and of 2-vinyloxycarbonyloxymethyl anthrachinone at 256, 317 and at $387 \mathrm{~nm}$ which are also very compatible with the output lines from a medium-pressure mercury lamp commonly used for crosslinking systems of this type.

\section{RESULTS AND DISCUSSION}

\section{1. Effect of copolymerizable photoinitiators on viscosity}

The solvent-based acrylic PSAs were synthesized with diverse conc ntrations investigated copolymerizable photoinitiators from 0.5 to $3.0 \mathrm{wt}$. \%. The cosities synthesized acrylic PSAs are presented in Fig. 4.

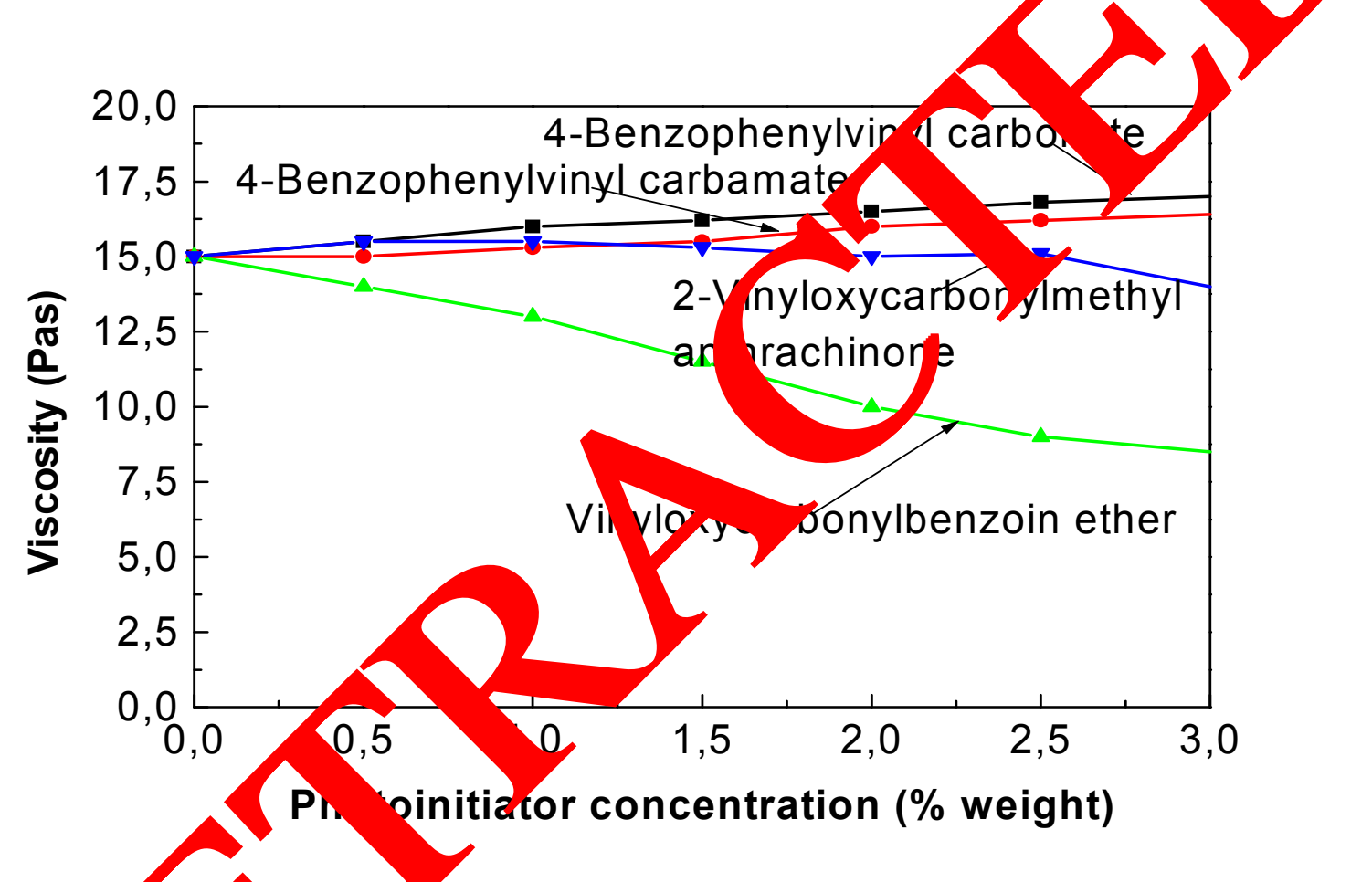

Figur 4. Infly nce of pho oinitiator concentration on viscosity of synthesized PSAs.

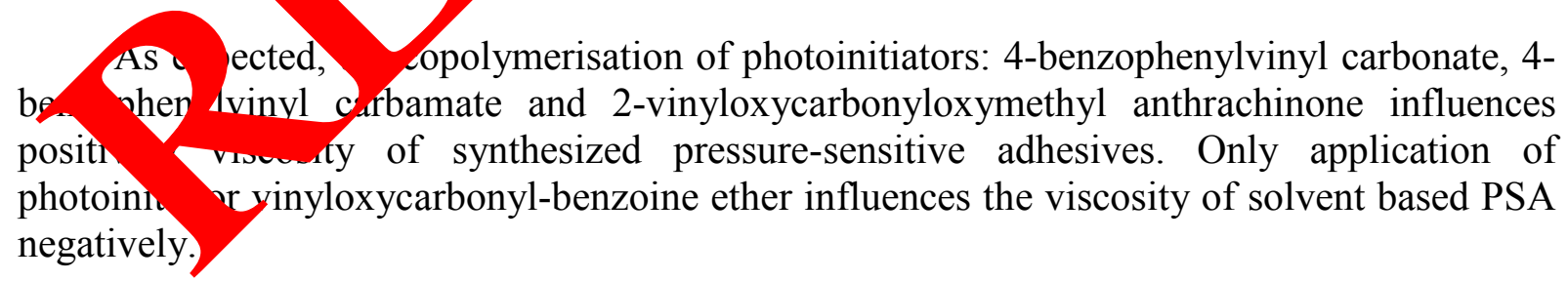

\section{2. Influence of copolymerizable photoinitiators on molecular mass}

The results of the influence of the investigated copolymerizable photoinitiators on molecular mass of solvent-based synthesized acrylic PSAs are presented in Fig. 5. 


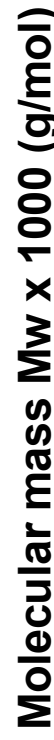

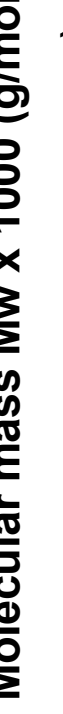

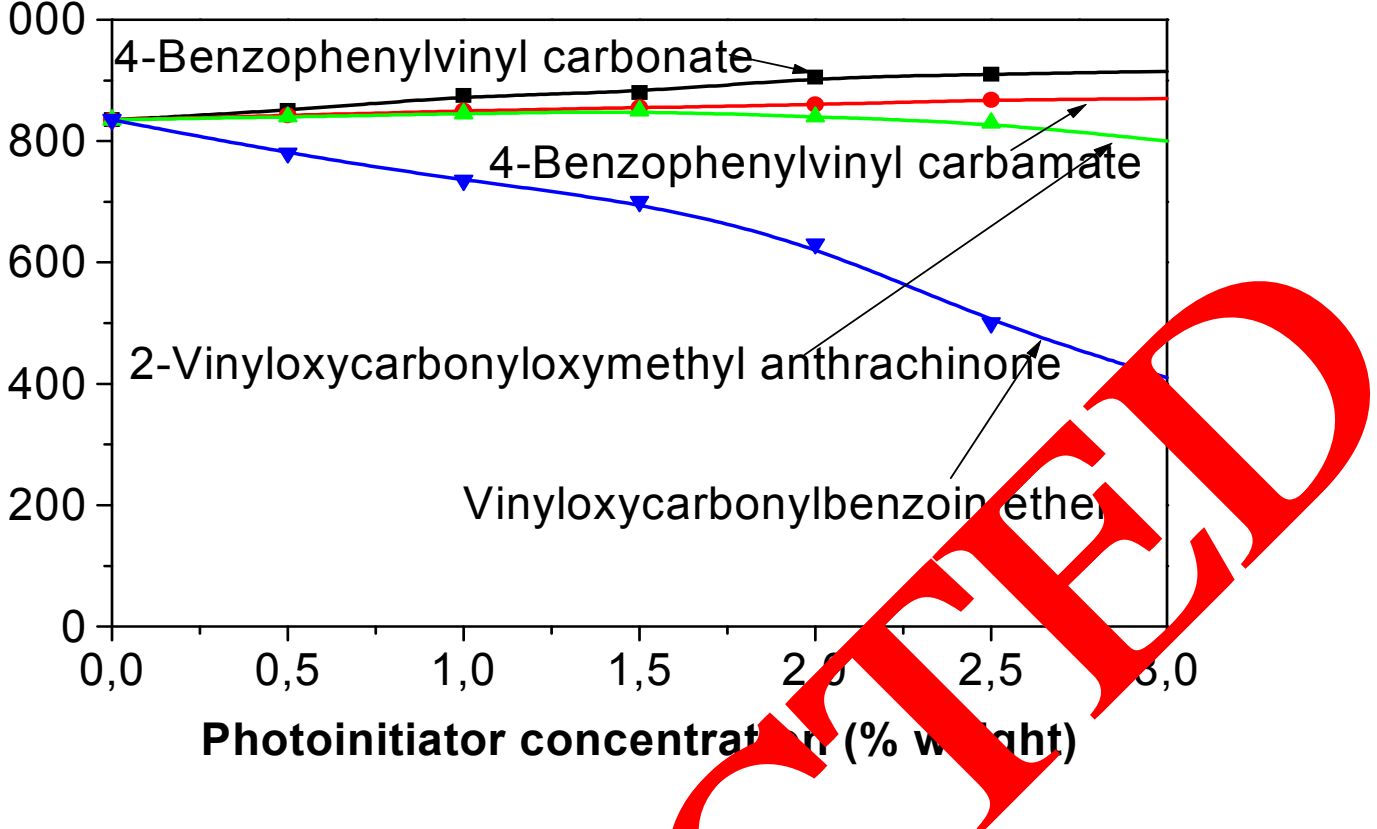

Figure 5. Effect of photoinitiator concentration of nolecular miss of synthesized PSAs.

\section{3. Influence of the photoinitiators conce on tack of synthesized PSAs}

The solvent-based pressure-sensitive ad es w es coated on polyester foil with coat weight of $60 \mathrm{~g} / \mathrm{m}^{2}$ and crosslinke coati o $30 \mathrm{~s}$ under UV-lamp. The results of tack, peel adhesion and shear strengt were lowed in Ygs. 6-8.

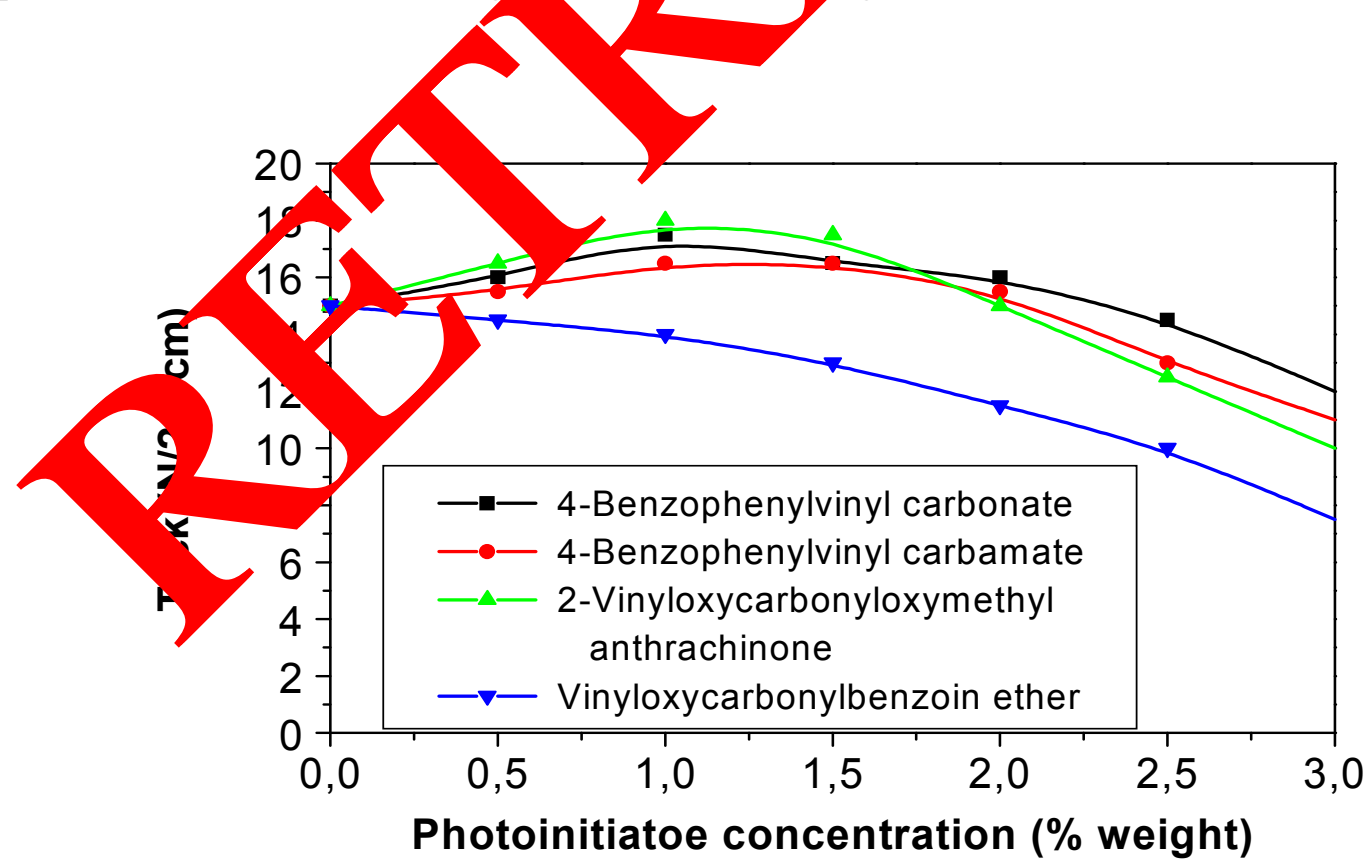

Figure 6. Tack of synthesized PSAs dependent on photoinitiator concentration. 


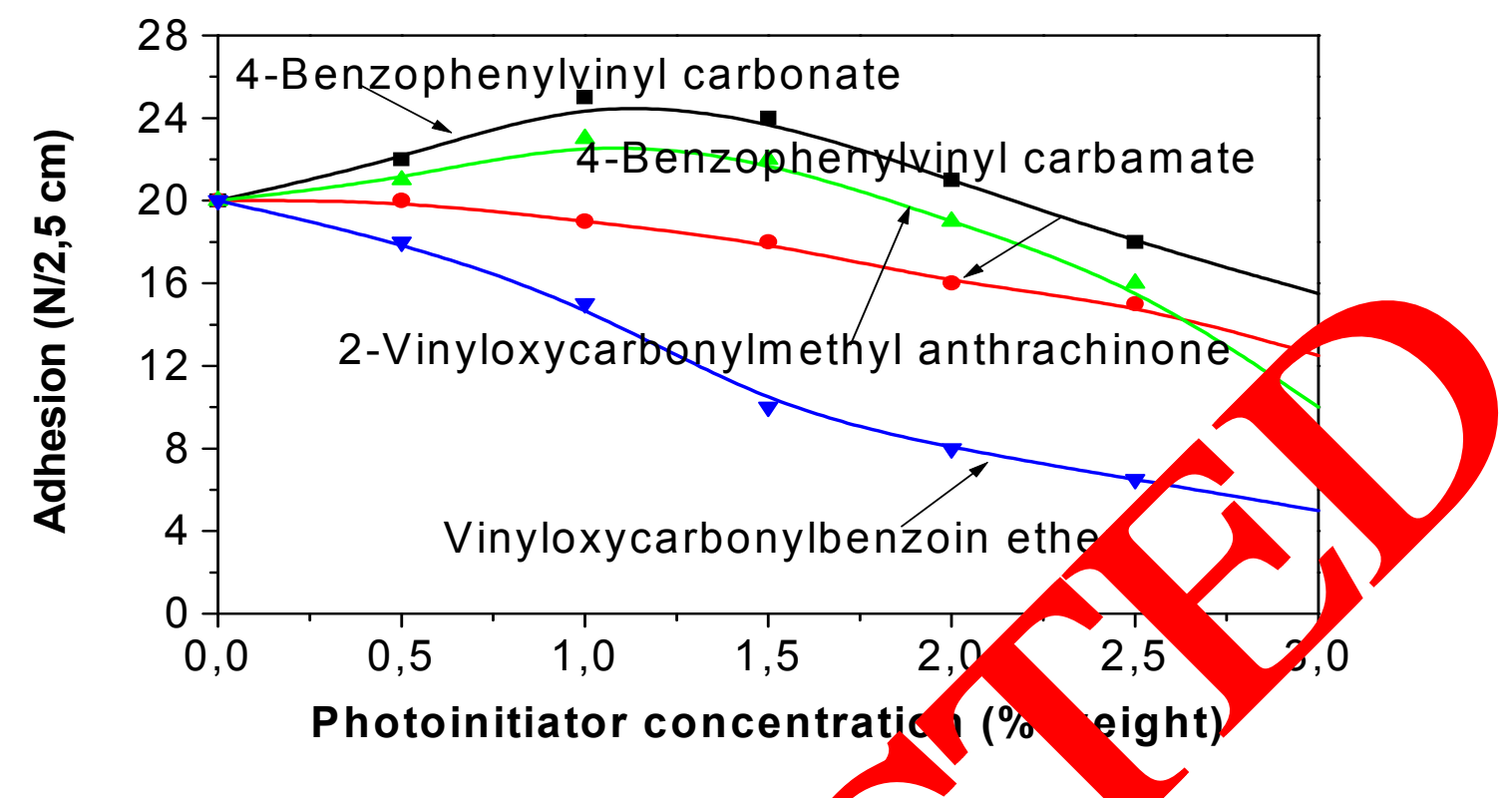

Figure 7. Peel adhesion of synthesized PSAs depe dent on photoinitia or concentration.

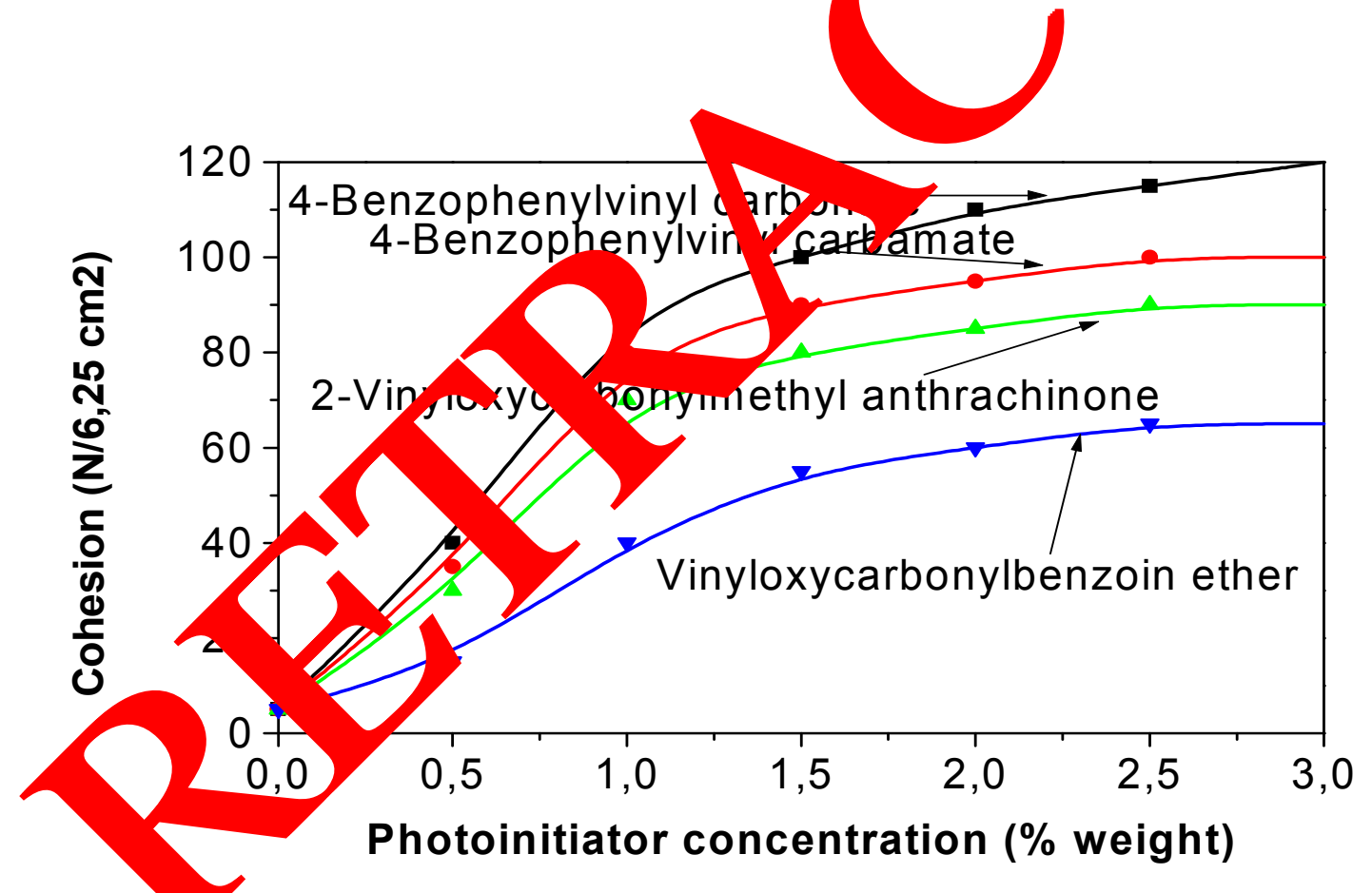

Figure 8. Shear strength of synthesized PSAs dependent on photoinitiator concentration.

The investigation of the influence of photoinitiator concentration on tack in case of UV-crosslinking of photoreactive acrylic pressure-sensitive adhesives enables it to be observed that the most efficient photoinitiator is 4-benzophenylvinyl carbonate. The highest value of tack was obtained by using of $1 \mathrm{wt}$. \% of this photoinitiator. The remaining two 
photoinitiators 4-benzophenylvinyl carbamate and 2-vinyloxycarbonyloxymethyl anthrachinone are not effective so much. The definitely least effective photoinitiator appeared vinyloxycarbonylbenzoine ether (Fig. 6).

4-benzophenylvinyl carbonate appeared also to be the most effective photoinitiator as to the investigated peel adhesion of the UV crosslinking acrylic pressure-sensitive adhesives. A maximal adhesion was noticed for the concentration of 1 wt. \% 4-benzophenylvinyl carbonate. Lower values of peel adhesion were received in case of the photoinitiators: 4benzophenylvinyl carbamate and 2-vinyloxycarbonyloxymethyl anthrachinone. Vinyloxycarbonylbenzoine ether was evidently the lowest effective photoinitiator.

The increase of the concentration of unsatureted photoinitiators in synthesi lic PSAs causes in general an increase of shear strength in the resulting adhe ives. A cohesion value of $90 \mathrm{~N}$ order of magnitude was possible to be obtained alreary applying wt. \% 4-benzophenylvinyl carbonate. Further increasing the con tratio of $t / s$ photoinitiator enables to increase shear strength up to 120 N. 4-benzo pheny vinyl a rate and 2-vinyloxycarbonyloxymethyl anthrachinone are a bit to effectrve than 4benzophenylvinyl carbonate. Vinyloxycarbonylbenzoine ether $\mathrm{p}$ on to be ne of the least effective photoinitiators, shear strength of $40 \mathrm{~N}$ being ined to $b$ ne of the least effective photoinitiators, shear strength of $40 \mathrm{~N}$ being attaip $\mathrm{d}$ fo e $1.5 \mathrm{wt}$. 0 concentration and shear strength of about $60 \mathrm{~N}$ being achieved on photoinitiator concentration.

\section{CONCLUSIONS}

From the evaluation of the experiments diso in this article, it can be concluded that all the investigated copolymerizable photoini at ors ca be used for polymerization and after polymerization to UV-initiated cr king of ressure sensitive adhesive acrylics. The UVabsorption curves of copolym izabl photoin ators shows strong absorption in areas of typical UV lamps and can we system. Generally 4-ber Lopreny vl carbonate, 4-benzophenylvinyl carbamate and 2vinyloxycarbonyloxyn a anthrach influences very little the viscosity of solvent based pressure sensitive hesi vinyloxycarbonylbenzoine ether decreases the viscosity of acrylic PSAs. Th similar a was observed for the influence of molecular mass of sinthesized se' adhe ve acrylic

Fron in estiga ed copolymerizable photoinitiators, the best results for relevant properties of pro re sen ave adhesives such as tack, peel adhesion and shear strength were given oy enzop vinyl carbonate. The highest values of tack, peel adhesion and shear str th $y$ re obse ved at concentration about $1 \%$ by weight of 4-benzophenylvinyl carbo operties of synthesized PSA containing 4-benzophenylvinyl carbonate are after UN osslinking excellent. The shear strength shows very high level. 


\section{References}

[1] Z. Czech, Crosslinking of Acrylic PSA, Publisher Szczecin University of Technology, 1999.

[2] E. Andrzejewska, Progress in Polymer Science 26 (2001) 605-665.

[3] W. Baeumer, M. Köhler, J. Ohngemach, Conference Proceedings Radcure 86, September 8-11, Baltimore, Maryland, USA (1986) 443-454.

[4] R. Milker, Z. Czech, Adhäsion 6 (1989) 20-25.

[5] Z. Czech, Polimery 4 (2002) 8-15.

[6] Z. Czech, W. Blum, F. Hermann, Patent WO 94/14853, (1993) Lohmann

[7] G. Auchter, Adhäsion 1/2 (1993) 14-20.

[8] Z. Czech, A. Butwin, J. Kabatc, J. Świderska, L. Shao, Y. Bai, Pe ner B (2012) 441-452.

[9] Z. Czech, A. Butwin, J. Kabatc, J. Świderska, Polymer Bu in 69 (201_ 00.

[10] Z. Czech, A. Kowalczyk, J. Kabatc, J. Świderska, Ey ean er Journal 48 (2012) 1446-1454.

[11] Z. Czech, Patent DE 19501025 (1995) Lohm n.

[12] Zbigniew Czech, Agnieszka Kowalczyk, Domi a Sowa, I ternational Letters of Chemistry, Physics and Astronomy 1 (2013) 63-0

[13] Zbigniew Czech, Dominika Sowa, Jago an International Letters of Chemistry, Physics and Astronomy $3(20 \quad 3 / 21-2)$

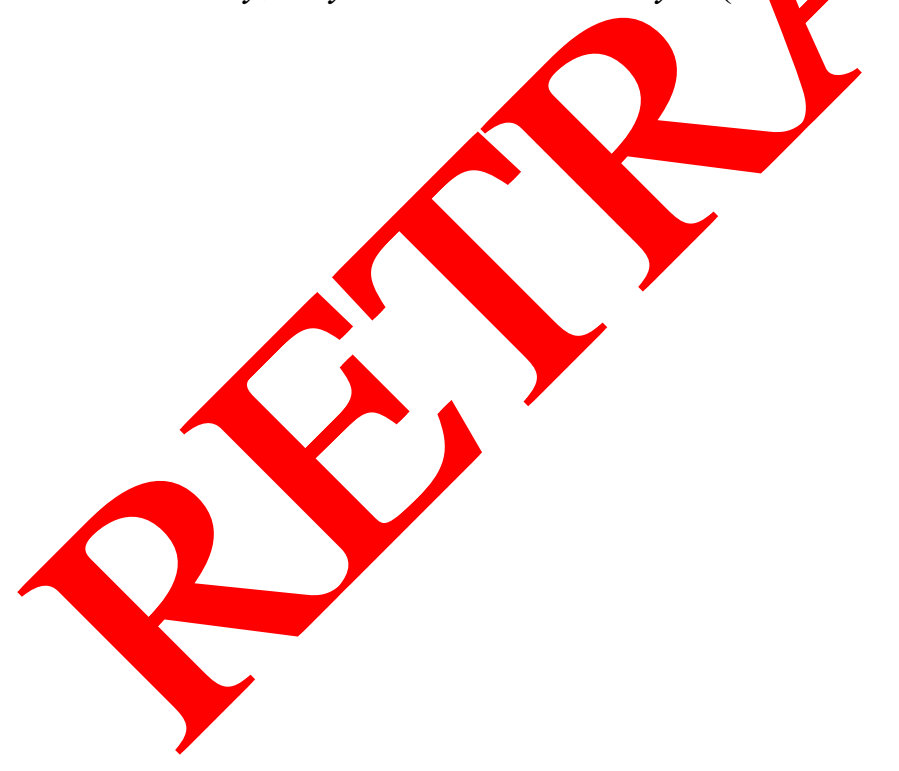

